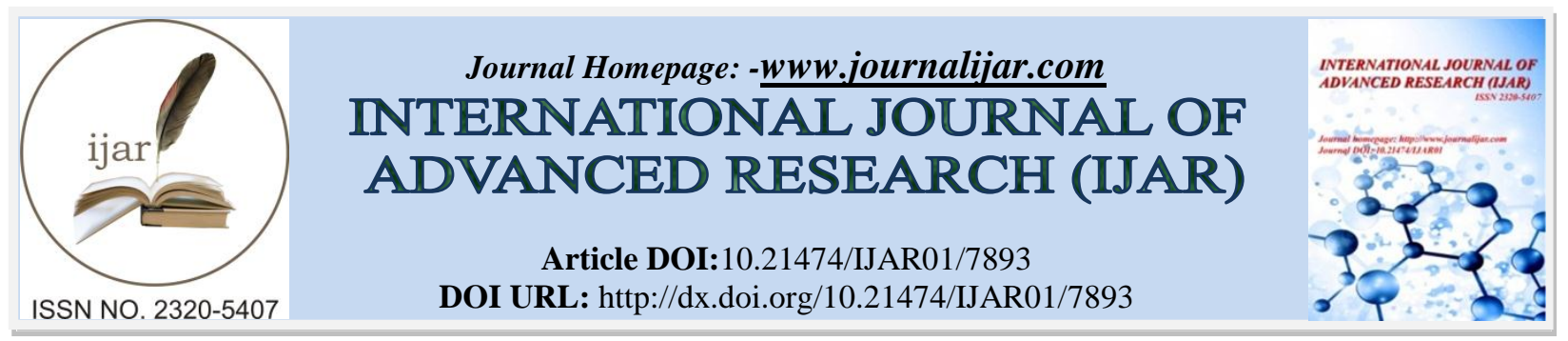

RESEARCH ARTICLE

\title{
FEEDING HABIT AND IMPACT OF VARIOUS PHYSICO-CHEMICAL PARAMETERS (I.E. TEMPERATURE, HUMIDITY, LIGHT INTENSITY) ON LIFE CYCLE STAGES OF KERATIN DIGESTIBLE INSECT TINEOLA BISSELLIELLA.
}

\author{
Subhamoy Das ${ }^{1}$, Avishek Dolai ${ }^{1}$, Rajkumar Guchhait ${ }^{1}$, Sagnik Mondal ${ }^{1}$, Manik Das ${ }^{1}$, Moumita Jana ${ }^{1}$, \\ Mousumi Ghorai ${ }^{1}$, Susmita samanta ${ }^{1}$, Bithi Bera ${ }^{1}$ and Samarpita Bhowmik ${ }^{1}$. \\ Dept. of Zoology, Mahishadal Raj College, Mahishadal, Purba Medinipur, West Bengal, India.
}

\section{Manuscript Info}

\section{Manuscript History}

Received: 11 August 2018

Final Accepted: 13 September 2018

Published: October 2018

Keywords:-

Keratin, waste management, Life cycle,

Tineola bisselliella, hair, food preference.

\begin{abstract}
Keratin is the protein extracted from skin modification such as horn, nail, wool, hair, claws. This protein is not easily digestible. Mainly hairs of human and cattle pollute the environment and also collapse our drainage system. For this type of waste management Tineola bisselliella shows the best result. We study their feeding behaviour in different parameter like pure hair; hair and salt water; hair and blood water; hair, dust and blood; hair and shampoo and hair and coconut oil. Among them hair with dust and blood is most preferable and clean hair means hair and shampoo is less preferable. We also study the impact of temperature, humidity and light intensity on different life cycle stages and how that parameters related to hair consumption that is also established.
\end{abstract}

Copy Right, IJAR, 2018,. All rights reserved.

\section{Introduction:-}

Structure and functions of keratin proteins were reported that it was simple, stratified, keratinized and cornified epithelia (Bragulla et al, 2009). Keratin was integral element of cells and its analogy, a review of collagen would also make sense only within the context of connective tissue structures (Wang, 2006; 8. Denecker et. Al. 2008). This keratin protein is indigestible in natural condition. In rural areas the hair is thrown away in environment and it slowly decomposes over several years. In urban areas it often accumulates in large amounts in the solid waste streams and chokes the drainage systems. Due to slow degradation it acts as dumps/waste. Leachate from these dumps increases the nitrogen concentration in the water bodies like pond, river, lake causing problems of eutrophication and burning of human hair produces foul odor and toxic gases such as ammonia, carbonyl sulphides, hydrogen sulphides, sulphur dioxide, phenols, nitriles, pyrroles, and pyridines (Brebu and Spiridon, 2011; Gupta A.,2014; Kumar et al, 2009). Zhelijazkov reported that hair waste were use as soil amendment and nutrient Source (Zheljazkov V. D., 2005; Yu et. Al., 1968). Impact of hot events at different developmental stages of a moth: the closer to adult stage, the less reproductive output (Zhang et al, 2015). Keratin can bedigested by Microsporum canis was reported by Daniels, G., 1953.

Our research focused on keratin digestible insect Tineola bisselliella. We study their life cycle stages and different physico-chemical parameters like temperature, humidity, light intensity and also study their feeding preferences among only hair; hair and salt water; hair and blood water; hair, dust and blood; hair and shampoo and hair and coconut oil. 


\section{Material And Methods:-}

Specimens were collected from old taxidermy of our departmental museum. They are kept in a glass aquarium $(5 \mathrm{ft} \times 3 \mathrm{ft} \times 2 \mathrm{ft})$ with ad libitum food and maintained proper temperature and humidity. All the experiment was done in ecology laboratory of department of Zoology, Mahishadal Raj College, Mahishadal, Purba Medinipur, West Bengal, India $\left(22.1865^{\circ} \mathrm{N}, 87.9837^{\circ} \mathrm{E}\right)$. Temperature and humidity reading were measured by 'Fluke TH $3-9 \mathrm{~V}$ Dual Display Relative Humidity Temperature Meter' and light intensity was measured by 'Fluke LM 200LED - 3.1/2 digit LED Light Meter'. All the experiment were done in separate glass aquarium created environment and repeated thrice.

\section{Result and discussion:-}

To see the feeding habit of Tineola bisselliella we set up this experiment. From our study it was well established that they were the special type of insect who digest the keratin containing hair.

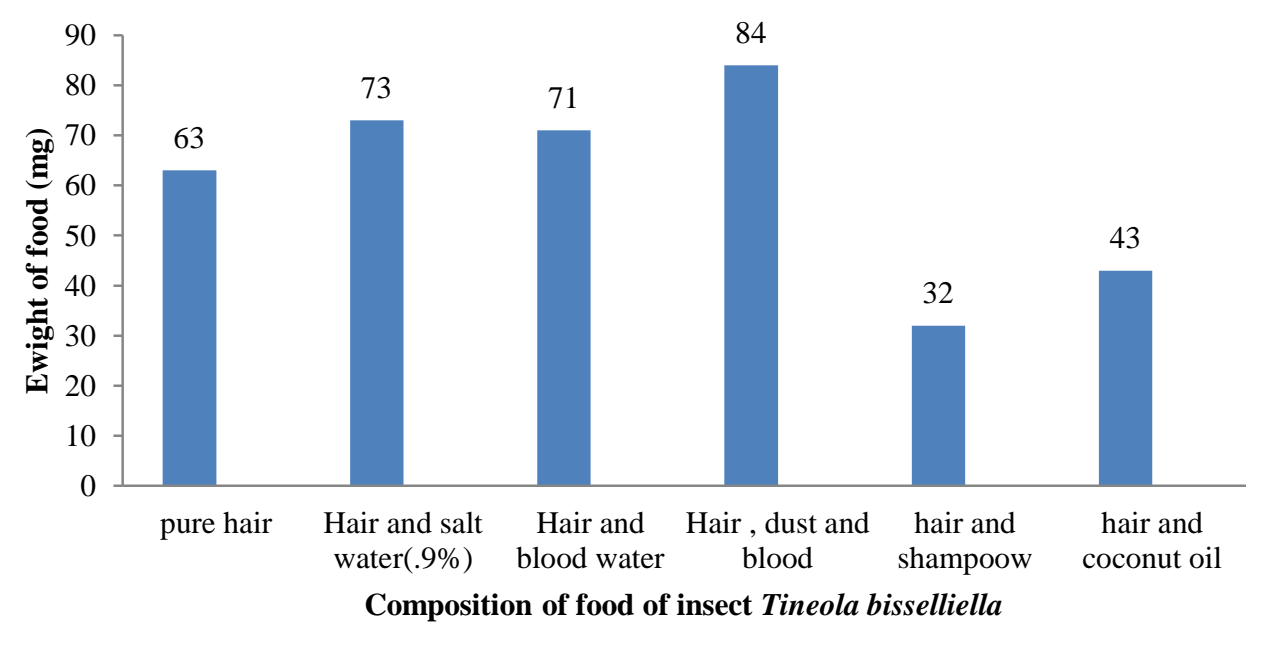

Fig 1:-Impact of food composition on hair deeding efficacy of insect Tineola bisselliella

For our experiment we take following combinations pure hair; hair and salt water (9\%); hair and blood water; hair, dust and blood; hair and shampoo and hair and coconut oil. Among them most of the time they prefer Hair, dust and blood together followed by hair and salt water followed by hair and blood water followed by pure hair followed by hair and coconut oil and lastly the silky hair means hair and shampoo treatment. It was clear that they prefer dirty hair than clean hair that were reflects in Fig-1.

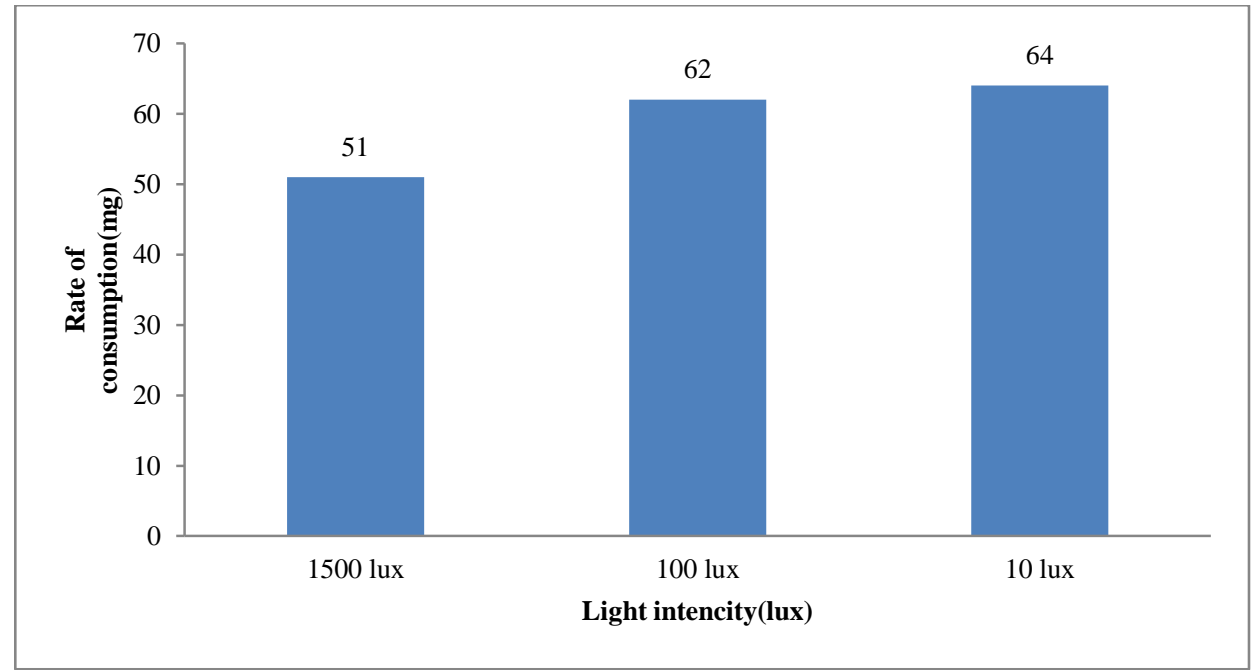

Fig-2:-Impact of light intensity on efficacy of hair consumption by insect Tineola bisselliella 
In Fig-2 we want to show that the efficacy of hair consumption by the insect in different light intensity that means dark (10 lux), dim light (100 lux) and the day light (1500 lux). Our result shows that they prefers low light for their livelihood. It was a important parameter for their consumption. If it was treated as pest so more light is necessary to keep it away.

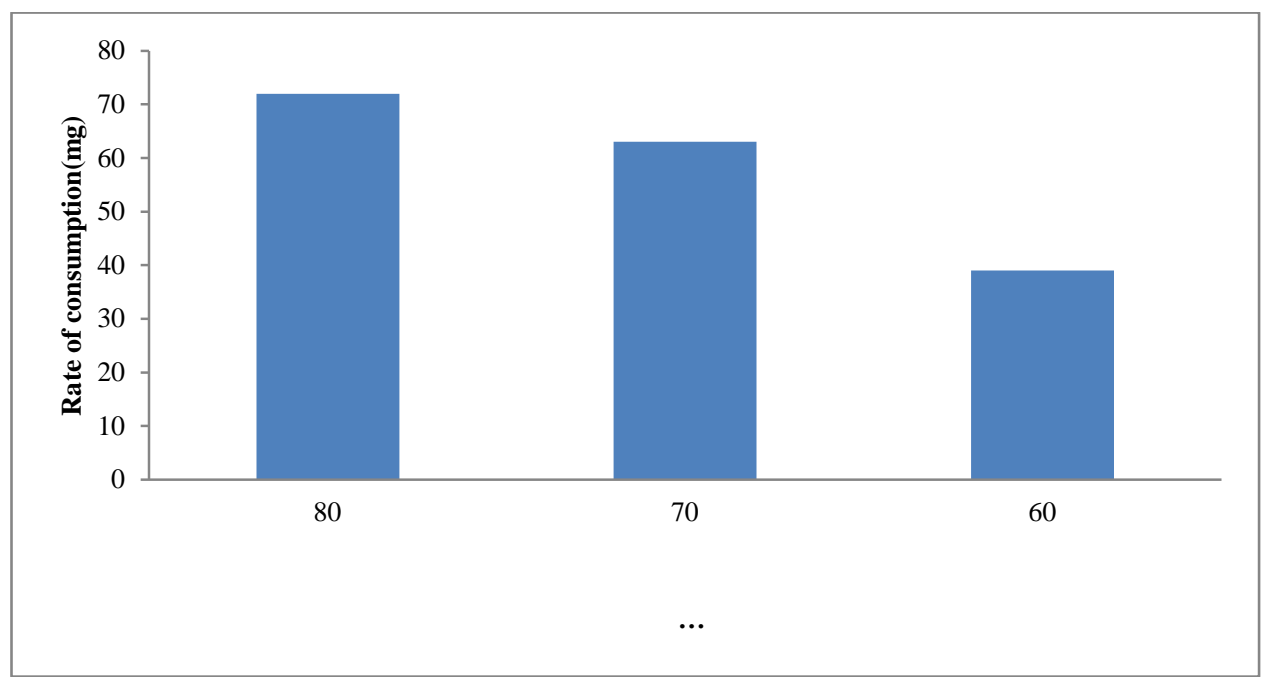

Fig-3:-Impact of humidity intencity on efficacy of hair consumption by insect Tineola bisselliella

From the Fig-3 it was clear that humidity plays a important role for their consumption. High range of humidity was their favorable condition and low range of humidity is adverse environmental condition to them.

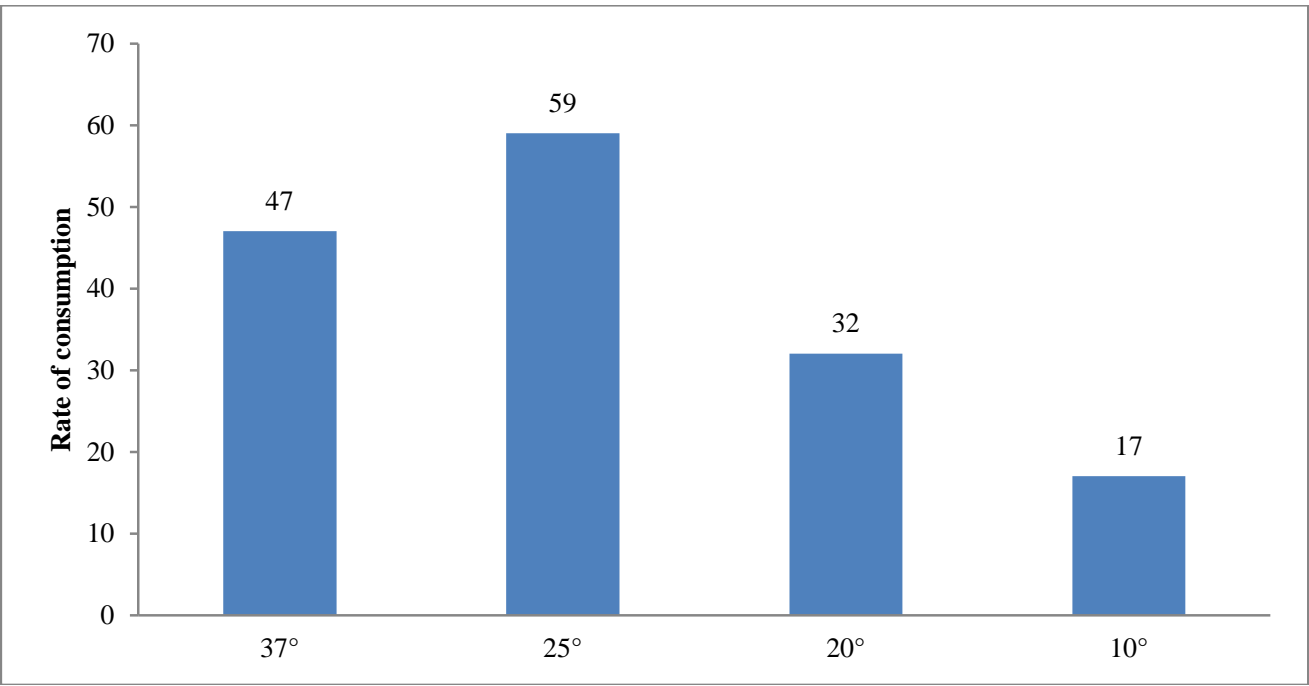

Fig-4:-Impact of Temperature intencity on efficacy of hair consumption by insect Tineola bisselliella

For showing the impact of temperature we take $10^{\circ} \mathrm{C}, 20^{\circ} \mathrm{C}, 25^{\circ} \mathrm{C}$ and $37^{\circ} \mathrm{C}$ temperature. Rate of consumption is higher in $25^{\circ} \mathrm{Ctemperature} \mathrm{followed} \mathrm{by} 37^{\circ}$ followed by $20^{\circ}$ and least at $10^{\circ}$ temperature which reflects in Fig- 4 . 


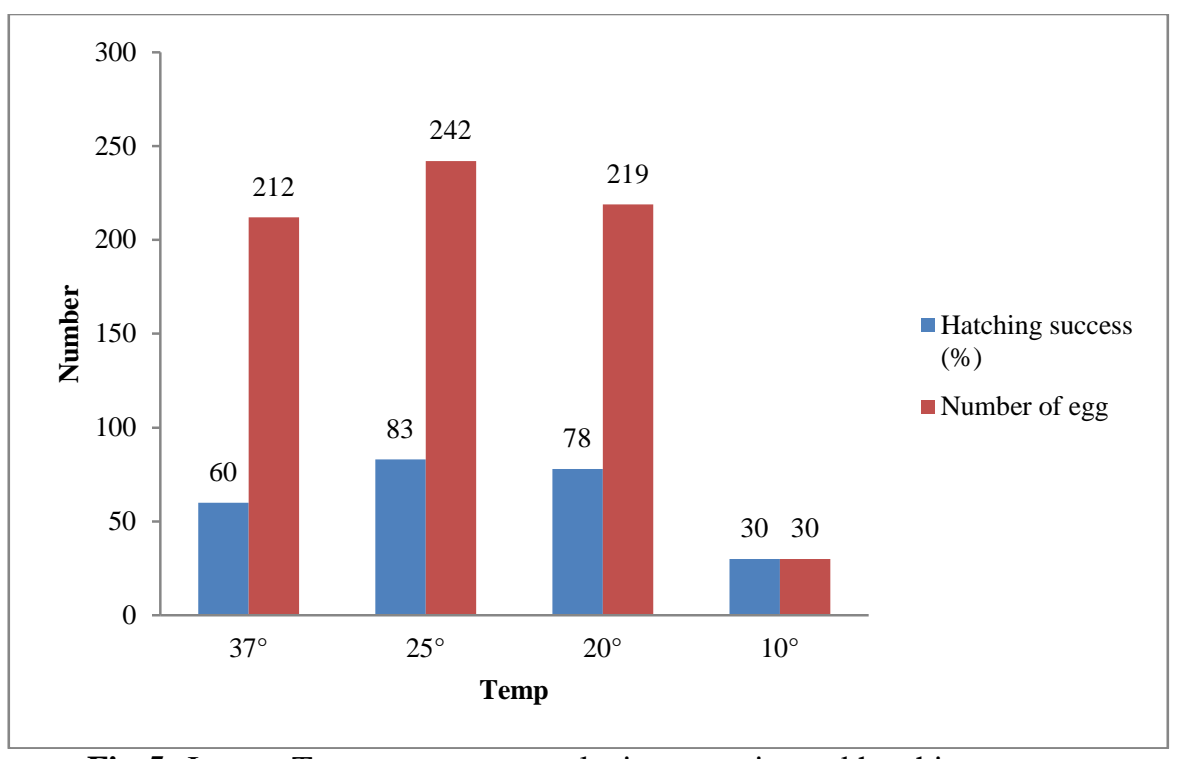

Fig-5:-Impact Temparature on egg laying capacity and hatching success

Number of egg production is taken the parameter for hatching success. In Fig-5 we saw that in $25^{\circ} \mathrm{C}$ temperature the hatching success is maximum that is 242 followed by $37^{\circ} \mathrm{C}$ temperature i.e. 212 followed by $20^{\circ} \mathrm{C}$ i.e. 219 and followed by $10^{\circ} \mathrm{C}$ i.e. 30 .

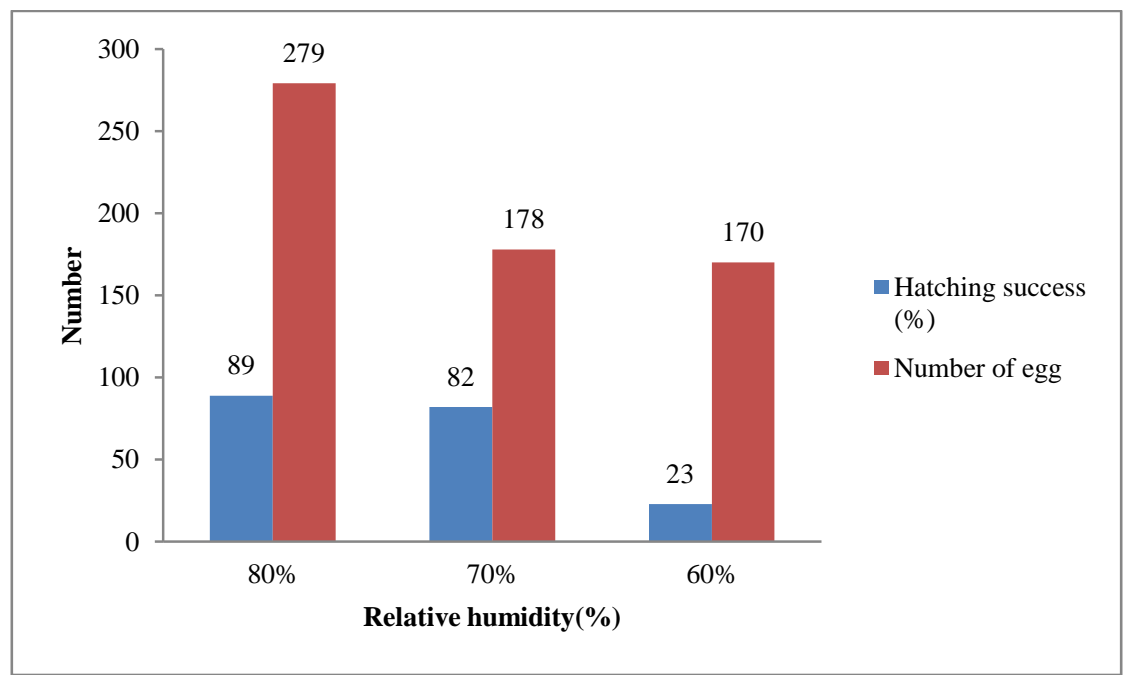

Fig-6:-Impact of relative humidity on egg laying capacity and hatching success

Our next target to show that how relative humidity affects the hatching success. Hare we show that in $80 \%$ humidity hatching success was 279 , in $70 \%$ humidity the hatching success was 178 and in $60 \%$ humidity the hatching success was 170 . So it was clear that more humidity is favorable to them. 


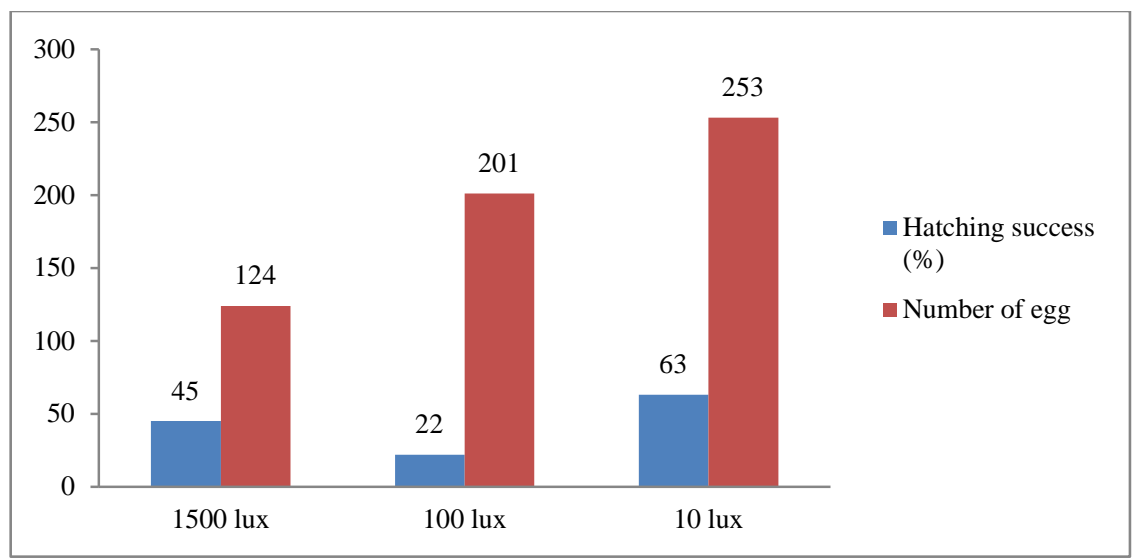

Fig-7:-Impact of light intensity on egg laying capacity and hatching success

Our third physico-chemical parameter was light intensity and research questions was how impact of light intensity on egg laying capacity and hatching success. In 10 lux light intensity hatching success and number of egg was 63 and 253 respectively and in 100 lux it was 22 and 201 respectively and in 1500 lux it was 45 and 124 respectively. So, in Fig-7 it was clear that low light supported the hatching success and number of eggs.

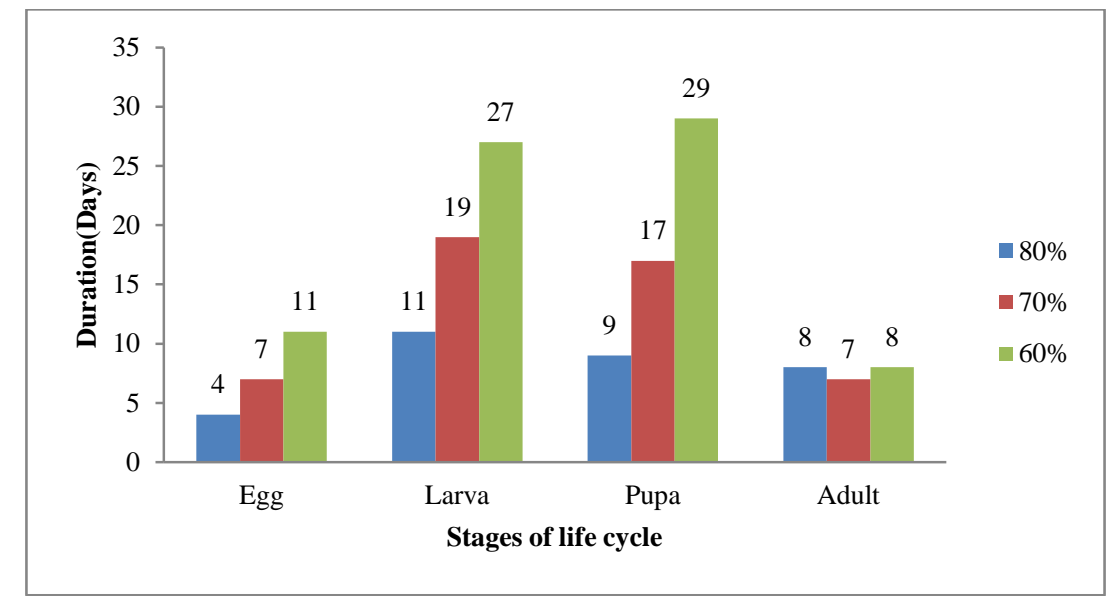

Fig-8:-Impact of relative humidity on duration of life cycle stages of insect Tineola bisselliella

We study the entire life cycle of Tineola bisselliella and show the how impact of relative humidity effects the different life cycle stages i.e. egg, larva, pupa and adult. In $60 \%$ humidity the duration of life span increase remarkably followed by $70 \%$ and $80 \%$. In case of egg formation $80 \%, 70 \%$ and $60 \%$ humidity supports their life span 4, 7 and 11 days respectively. In case of larvae it was 11, 19 and 27 days respectively. In case of pupa it was 9,17 and 29 respectively and in case of Adult it shows more or less equal life span that was 8,7 and 8 respectively.

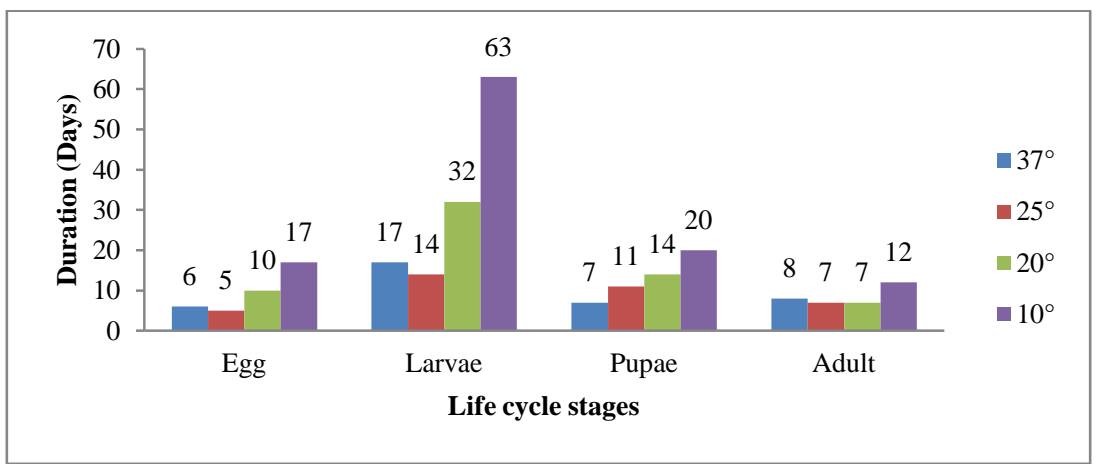

Fig-9:-Impact of Temparature on duration of life cycle stages of insect Tineola bisselliella 
Temperature also a key factor for their life span. In $25^{\circ} \mathrm{C}$ temperature duration of life cycle was least. From Fig-9 we found that $37^{\circ} \mathrm{C}, 25^{\circ} \mathrm{C}, 20^{\circ} \mathrm{C}$ and $10^{\circ} \mathrm{C}$ affects the duration of hatching of egg $6,5,10$ and 17 respectively. In case of larvae it was 17, 14, 32 and 63. In case of pupae it was 7, 11, 14 and 20. In case of adult it was 8, 7, 7 and 12 respectively.

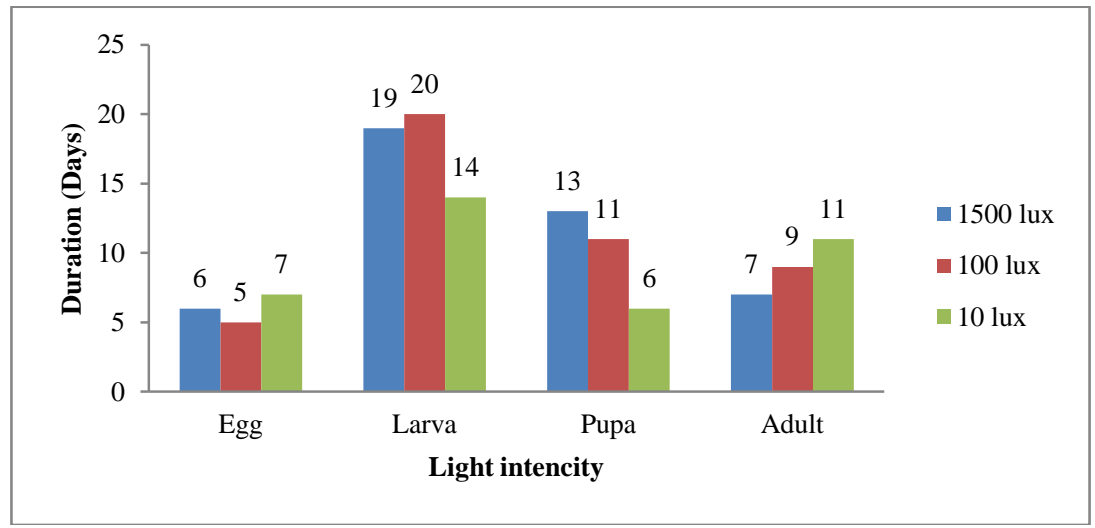

Fig-10:-Impact of light intensity on duration of life cycle stages of insect Tineola bisselliella

Light intensity also a important factor in their life cycle. Three different light intensity that was described earlier was taken i.e. 1500 lux, 100 lux and 10 lux respectively and their correspondence effect on egg was 6,5 and 7 respectively. In case of larva it was 19, 20 and 14 respectively. In case of pupa it was 13, 11 and 16 respectively and in case of adult it was 7, 9 and 11 respectively.

From our result it was clear that temperature, humidity, light intensity were the important physico-chemical parameter in their life cycle. Their feeding habit and food preference also be cleared. If we want to use this insect for waste management for hair waste those information helps a lot.

\section{Acknowledgement:-}

The authors are thankfully acknowledged the Principal of Mahishadal Raj College to provide the permission to conduct the research in the College. In the same time we are thankful to UGC (minor research project), for financial support (Sanc. No. - PSW-140-14-15 (ERO), Datad-3.2.2015). The authors are also acknowledged to students of Department of Zoology, Mahishadal Raj College.

\section{References:-}

1. Bragulla H. H. and Homberger D. G. (2009) Structure and functions of keratin proteins in simple, stratified, keratinized and cornified epithelia. J. Anat., 214, 516-559

2. Brebu M. and Spiridon I. (2011) Termal degradation of keratin waste. Journal of Analytical and Applied Pyrolysis, 91(2), 288-295.

3. Daniels G. (1953) The Digestion of Human Hair Keratin by Microsporum canis Bodin. Microbiology 8(2):289294 doi:10.1099/00221287-8-2-289

4. Denecker G, Ovaere P, Vandenabeele P, Declercq W (2008) Caspase-14 reveals its secrets. J Cell Biol 180, 451-458.

5. Gupta A. (2014) "Human Hair "Waste" and Its Utilization: Gaps and Possibilities," Journal of Waste Management, 17. https://doi.org/10.1155/2014/498018.

6. Kumar S., Bhattacharyya J. K., Vaidya A. N., Chakrabarti T., Devotta S., and Akolkar A. B.( 2009) "Assessment of the status of municipal solid waste management in metro cities, state capitals, class I cities, and class II towns in India: an insight," Waste Management, 29(2), 883-895.

7. Wang JHC (2006) Mechanobiology of tendon. J Biomech, 39, 1563-1582

8. Yu, R. J., Harmon, S. R. and Blank, F. (1968) Isolation and purification of an extracellular keratinase of Trichophyton mentagrophytes. J. Bact., 96(1435).

9. Zhang, W. et al. (2015). Impact of hot events at different developmental stages of a moth: the closer to adult stage, the less reproductive output. Sci. Rep., 5, 10436; doi: 10.1038/srep10436

10. Zheljazkov V. D. (2005) Assessment of Wool Waste and Hair Waste as Soil Amendment and Nutrient Source. Journal of Environmental Quality Abstract - Waste Management, 34(6), 2310-2317. 